\title{
Entangled interpretations and a transnational art exhibition:The case of (...) Ketsin! Art from the Kyrgyz Republic (Shoreditch, May 2013) ${ }^{1}$
}

Sally Nikoline Cummings*

\begin{abstract}
Through the case study of a visual arts exhibition on the Kyrgyz Revolution, (...) Ketsin! (May 2013), this article traces the complex set of factors that influence how a transnational exhibition is interpreted. Combining literatures on visual representation, the role of intentionality in authorship, and, museum and gallery studies, I propose here the notion of 'entangled interpretations' to convey the overlapping and muddled layers rather than discrete parts that together constitute interpretation. These layers comprise: the artworks; other works in the same genre and other works by the same artists; the exhibition design and display; the architecture of the venue; the artists' intentions; the roles of commissioner, sponsor and curator; and, the split audience: original and intended.
\end{abstract}

Key words: exhibition; interpretation; transcultural; Kyrgyz Republic; visual arts.

\section{Introduction}

On a bright May morning in 2013, a group of Kyrgyz artists gathered outside Shoreditch Town Hall to survey the busy London traffic. The vista included London's iconic double deckers, black taxis and the majestic architecture of a centre of world commerce, far removed from the rush hour of their home capital Bishkek. Before too long the artists disappeared back into the Hall's basement to resume the mounting of their exhibition, (...)Ketsin! Art from the Kyrgyz Republic. The London site was its première, generously sponsored by Glasgow University's CRCEES, the British Academy and the Arts and Humanities Research Council. Conceived as an exhibition on revolution, the various installations were created in the aftermath of the profound changes that swept the Kyrgyz Republic in 2005, when popular protests saw the removal of their first president, Askar Akaev.

The interpretation of transnational art exhibitions matters on several levels (Whitehead 2011). First, they offer a specific platform to visually explore debates on the factors that feed into the process of interpretation. Alasdair Maclntyre (1984: 76) calls a world without interpretation 'a world of textures, shapes, smells, sensations, sounds and nothing more' that 'invites no questions and gives no grounds for furnishing any answers.' Second, visual representations play significant roles in communicating affect, an effective window on uncovering the meaning of events. Third, art exhibitions offer a way of transculturally communicating major themes and events; by circumventing linguistic barriers, they can attempt to communicate, in this case for example, what was experienced by a population at a major political juncture of their country's transformation.

The works in this particular exhibition were specially commissioned by the author when, in late 2008, I proposed to artists Evgeny Boikov and Furkat Tursunov the idea of artistically conveying the emotions experienced by the citizens of this small mountainous Central Asian republic at the time of the 2005 revolution. I had become familiar with the works of these artists during earlier research in the Kyrgyz Republic. Events then assumed their own dynamic and they were superseded by a second revolution in April 2010 which in turn removed Akaev's successor, Kurmanbek Bakiev. The power vacuum that resulted formed the backdrop to the intercommunal violence of Osh in June 2010, which left hundreds dead and tens of thousands internally displaced and refugees. The artists, however, continued to focus in their output primarily 
on 2005, with some incorporation of 2010 and one exhibit only related to the Osh events. The exhibition ran in London for a week in May 2013 and was entitled (...) Ketsin!, meaning 'Step Down!' in Kyrgyz which was chanted on the streets by the crowds in both revolutions. (...) is left blank for the name of the specific president that crowds are chanting, indicative of the repetitive nature of revolution in this Central Asian republic.

Through an analysis of this exhibition I seek to explore the factors that contribute to how transnational art exhibitions are interpreted and create knowledge. The knowledge in this case concerns political transformation in the Kyrgyz Republic. Through their interpretation of (...) Ketsin!, exhibition visitors depart with new knowledge or confirm their existing knowledge. The exhibition offers a new case study to reflect further on the debate that centre around interpretation. These debates have a long lineage, but their relevance remains high and far from resolved; they tackle especially the question of whether any particular interpretation is more correct than another and whether our aim should in any case be to establish whose interpretation is correct.

The salience of this question was highlighted in the Keynote Address made by Cheryl Meszaros at the Visitor Studies Association Conference at the Grand Rapids in Michigan in July 2006. Meszaros (2006: 12) points to the 'exile of received knowledge' and the invasion of 'the "whatever" interpretation' as the structures and codes of the text were shifted to the individual reader. Furthermore,

[O]ne of the problems that arose when this productive and generative agency was granted to the interpreter was a loss of any definitive, authoritative, or even widely shared interpretation of a given text or work. Once the texts of the world were separated from their authors' intent and subsequently separated from a stable decoding system, they could simply float, adrift on the endless sea of innumerable interpretations.

(...) Ketsin! did evoke 'innumerable interpretations' among its visitors, but this should not necessarily be regarded as failure. I shall further argue that these multiple interpretations were less a function of singular, situational interpretation (which Meszaros argues is at the heart of the 'whatever') than a function of a) the display/architecture and b) the audience that split into an original and target audience. I also aim to show that transnational exhibitions, as opposed to, say, local or museum exhibits, have specificities that weigh differently in the interpretation process. Furthermore, (...) Ketsin!, confirmed, rather than created, new factual knowledge about the Revolution. It did, however, through the appeal to emotions, impart a sense of what this spectacular event meant to the participant and witness.

\section{Interpretation: concept and process}

It is not the purpose of this piece to revisit the already fertile ground telling the history of interpretation, but I will briefly introduce how the concept and process of interpretation feed into my own analysis. The definition of interpretation remains contested, and to a degree depends on the disciplinary origins and question focus of the definer, but generally interpretation refers to a communicative process that helps people make sense of, and understand more about, a site, collection or event. Debates on the relationship between intentions and interpretation, largely emanating from the philosophy of art, had a strong coalescence point around the author and the style and context that influenced his or her work. This, Meszaros (2006: 1011) further says, led to the three fallacies: the intentional fallacy ('real meaning of author's intent'); the genetic fallacy (intent in the context of production) and the pathetic fallacy (how emphatic qualities signal intent) which, by the early twentieth century, had been replaced by an emphasis on either structuralism or hermeneutics. Whilst structuralism focused on broader systems analysis such as linguistics, hermeneutics emphasized how meaning is made by the individual subject, the main topic of Meszaros' address.

This trajectory of interpretation influenced my choice of three conceptual approaches to explore (...) Ketsin!. They are, in no particular order of importance: John Falk and Lynn Dierking's (2000) contextual model; Christopher Whitehead's (2012) interpretive frames and Abigail Housen (1983) and Philip Yenawine's Visual Thinking Strategies (VTS).

Falk and Dierking's Contextual Model of Learning identifies three contexts that an 
individual brings to a learning situation (in this case an exhibition visit): personal, sociocultural and physical contexts over time. The personal is the sum total of personal and genetic history - building upon constructivist theories of learning where prior knowledge and experience, plus motivation, feed into a person's interpretation; the sociocultural refers to both the cultural value placed upon learning and the cultural context of the museum within society; finally, the physical refers to the physical context of the museum itself. Together they identified twelve factors of the personal, sociocultural and physical that together contribute to the quality of a museum experience. ${ }^{2}$ Relevant also for this article is how they (2008: 24) underscore that 'the relative importance of any one of these factors may vary between particular visitors and venues (e.g., science centers, natural history museums, zoos, planetaria, nature centers, etc.).'

Whilst referring to similar factors, Christopher Whitehead (2012) places emphasis on the act of engagingly interpreting rather than on the contextual input of that interpreting. This engagement occurs through a series of 'frames', amounting to an experiential approach in the study of interpretation. To frame the interpretive experience, Whitehead draws on Visual Thinking Strategies (VTS) and the five stages of aesthetics developed by cognitive psychologist Abigail Housen in collaboration with museum educator Philip Yenawine. ${ }^{3}$ Yenawine (1997) earlier developed the notion of visual literacy which he describes as

\begin{abstract}
...the ability to find meaning in imagery. It involves a set of skills ranging from simple identification (naming what one sees) to complex interpretation on contextual, metaphoric and philosophical levels. Many aspects of cognition are called upon, such as personal association, questioning, speculating, analyzing, fact-finding, and categorizing. Objective understanding is the premise of much of this literacy, but subjective and affective aspects of knowing are equally important.
\end{abstract}

\title{
Method and Methodologies
}

I combine the insights of these three concepts. Such eclecticism is not new - museum studies has long been informed by broader questions of theory and evidence to better understand their influence on how displays are presented and received. What I emphasize, however, is the 'entangled' nature of the factors behind interpretation: they relate to each other not in discrete parts but in overlapping and muddled layers. I also suggest those factors that matter more for a transnational art exhibition of this kind.

Writing in Museum Anthropology, Stephanie Moser (2010: 22) featured many of the factors I had come to identify in this eclectic approach. Her eight criteria relate to 'museum displays' and she identifies: architecture, location setting; space; design, color, light; subject, message, text; layout; display types; exhibition style; and, audience and reception. In relation to (...) Ketsin!, I added the intentions of the author and curator. I also incorporated a broader understanding of audience as split between original and intended. The upshot is seven factors (in which I fuse Moser's design, layout and display type): (1) the artworks - here the artwork as autonomous product whose interpretation is best sought in its artistic and aesthetic properties; (2) other works in the same genre and other works by the same artist; (3) the exhibition design and display; (4) the architecture of the venue; (5) the artists' intentions; (6) the role of commissioner, sponsor and curator; and, (7) the split audience: original and intended.

While I do not use their terms, the work of Falk and Dierking and Whitehead inform (1)-(7) in the following manner. The first two factors are captured by Whitehead's interpretive frames of 'technical-style' and 'narrative and pictorial' and in Falk and Dierking's model form part of the personal context. Factors (3) and (4) speak to Whitehead's 'architectural frame' and to Falk and Dierking's physical context. Whitehead terms (5) both the 'biographical frame' and the 'intentional-explanatory frame' and (6) the 'political'. My (7) refers to the audience as sociocultural context. Unlike my (1) and (2), here I refer to how either sociocultural provenance or knowledge (in this case related to the Kyrgyz Republic) is an interpretive frame for the onlooker.

Methodologically, I combined contextual interpretation with open-ended interviews with 15 visitors to the exhibition. ${ }^{4}$ For contextual interpretation I interviewed the two artists on several occasions, investigated broader sociocultural factors of the Kyrgyz Republic, and explored the physicality of the basement of Shoreditch Town Hall as a display setting. With the 
15 visitors to the exhibition I established first their social origins, profession and motivations for viewing (...)Ketsin!. After the visitors had had the chance to familiarize themselves with the exhibition, I accompanied them on a survey of each installation, asking simply a question either in Russian or English on the lines of 'What is the meaning here?', then allowing the viewer to think out loud with no intermittent directed questioning. I have used unstructured interviewing in several previous research projects and the method used here bears some likeness to VTS.

\section{Artwork as autonomous product}

A starting point for unpacking the interpretation process is to view the artwork as autonomous and to assess how its artistic aesthetic properties work to convey a message or an emotion or both. (...) Ketsin! consists of 11 exhibits that count as conceptual art, of which two were installations, two video art, three photographic print series and the remaining a combination of photographs and paintings. Because the labels that accompany the images are written by the artists rather than the curator, picture and text need to be considered simultaneously. The labels therefore depart from most permanent museum exhibition counterparts in that they were not provided by either the curator, or the museum or gallery's education department. For the sake of space, I focus here on eight exhibits (6 of which are pictorially included here): The Kinematics of Protest (Image 1); Dove of Peace Drawn by a Ram; Revolution Museum (Image 2); Beneath My Skin; Friendship Forever (Image 3); Asian Eyes (Image 4); Reprint (Image 5); and, Repairing Akaev (Image 6a and b).

The content and form of the eight exhibits convey four main emotional stages of the unfolding of the revolution: euphoria, insecurity, disappointment and cynicism. Two, The Kinematics of Protest and Dove of Peace Drawn by a Ram, display optimism around the creation of revolutionary change. The technology of production conveys this potential of transformation.

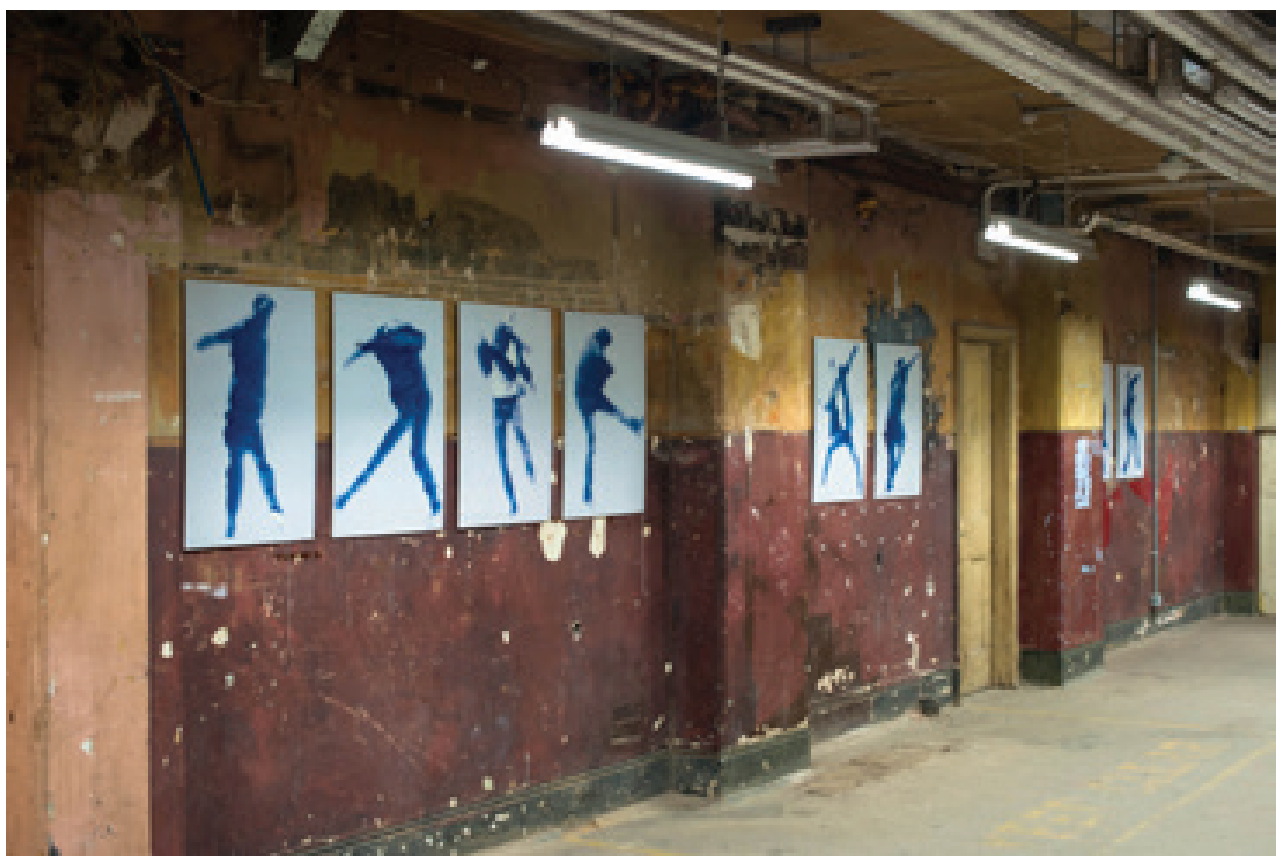

Image 1. Kinematics of Protest

The images in The Kinematics of Protest are a series of graphics, based on parts of photos taken during the two revolutions in Kyrgyzstan in 2005 and 2010, the text explaining how they display the '[d]ynamics of gestures and poses of individuals in extreme situations - 
significant and identical for all protests and revolutions around the world. But there the small differences matter.' These differences are accentuated through form - each of the reprints is slightly different in form, and suggests an infinite number of possibilities. Dove of Peace Drawn by a Ram is a variant on a Picasso painting but here appears in the form of a video installation projected from one of the Shoreditch alcove rooms. Boikov used a ram to paint a dove by dipping its trotters into white paint and from the white splurge teasing out the image of a dove. One London-based artist interpreted the video installation,

as a symbol of the everyday, the foodstuff, the people, the youth, that contrasts with the universal and soaring symbol of the pure white dove of peace. The act of using the ram to paint the dove takes the work one step on from Picasso's reflection on peace and suffering to suggest that the former may be a product of the latter. This is the most optimistic work in the exhibition.

Hope is juxtaposed to fear, suspicion and insecurity in the moment of protest, however, and two further displays capture this ambiguity. Revolution Museum, located in an unlit room, consists of 30 five by five-inch monitors positioned side-by-side on a table. Each monitor displays a different set of eyes, periodically blinking. The accompanying text reads:

The work creates a feeling that in the epoch of revolutions all our deeds, whether good or bad, will be spied on and evaluated. All social revolutions are made by one set of individuals in the interest of another set of individuals, while the majority of people are left out of this process.

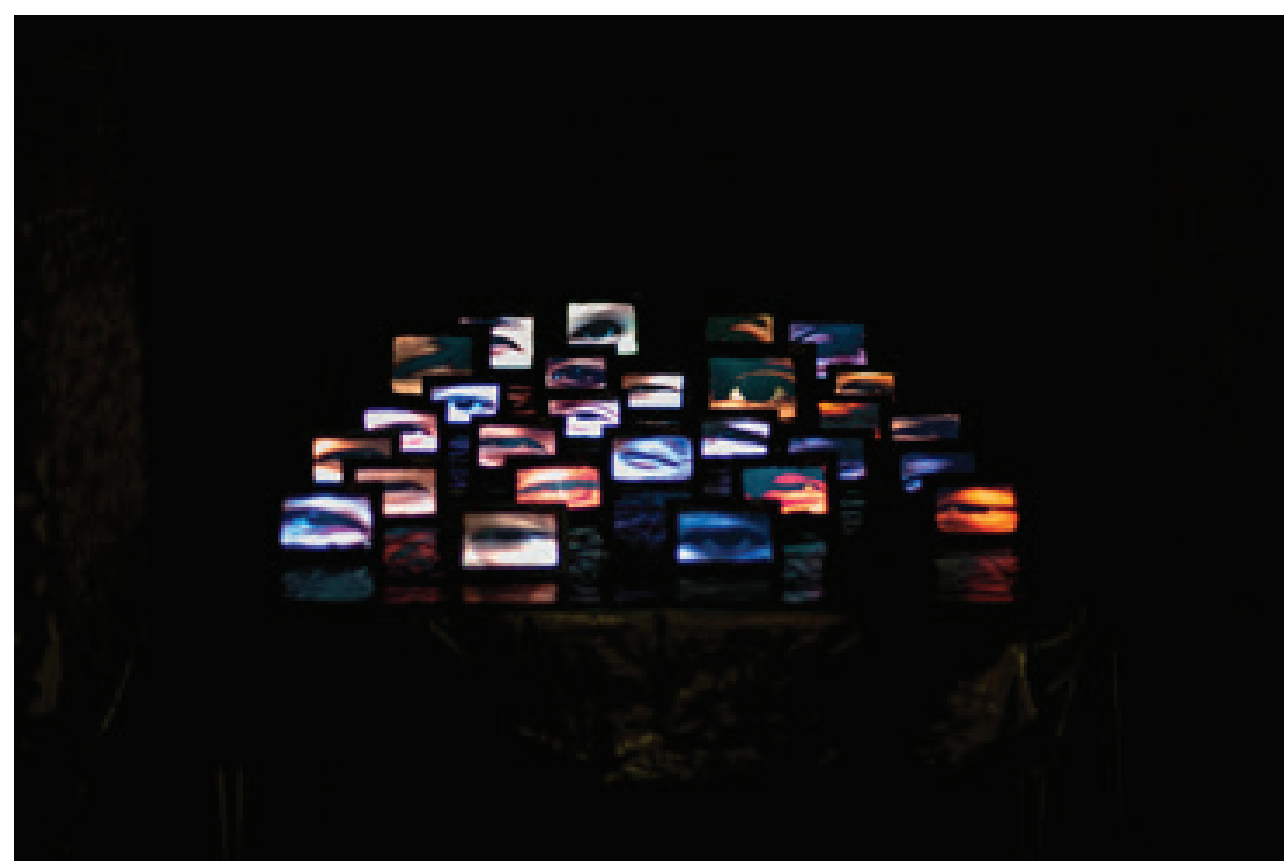

Image 2. Revolution Museum

By regrouping several pairs of eyes that do not look at each other, the installation conveys mutual suspicion rather than collective action. Surveillance trumps freedom. Beneath My Skin depicts a person's back, pockmarked with red circles. These red circles mark disruption: the accompanying label explains that the artist was having coffee with a friend when he was interrupted by a telephone call from his frightened wife relaying gunshots near their home. Over 
time these disruptions fade, but even if externally they are no longer visible, the unleashed feelings of unease and fear have become internalized.

Third, as the revolution settles and a power vacuum ensues, broader underlying anxieties resurface, particularly around issues of identity, self and other.

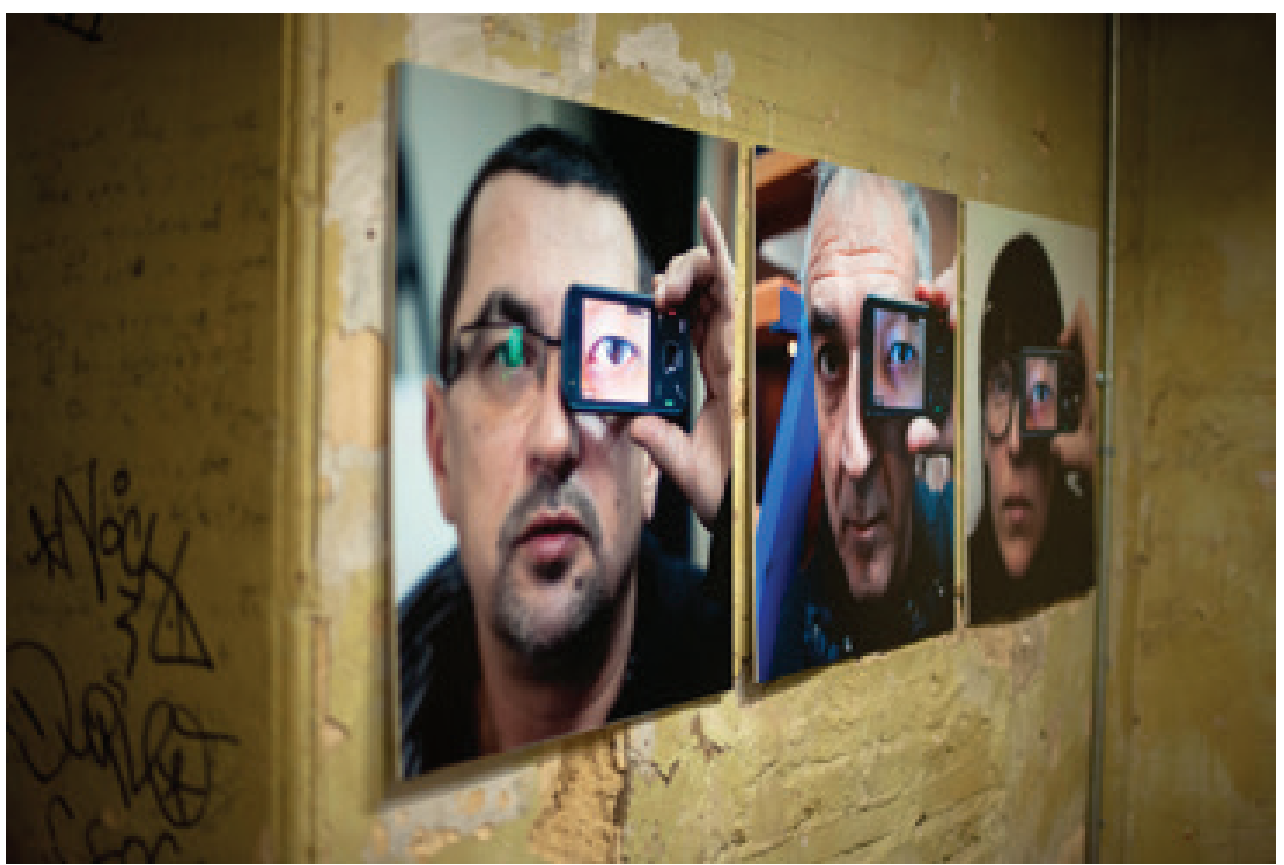

Image 3. Asian Eyes

In Asian Eyes, the eye perceived through the mobile telephone does not fit neatly into the face, and the accompanying text explains how,

[A] 'different eye' can be incorporated into the portraits or photos of various people with the help of a mobile phone. These include the change of one's core essence and identity, new vision of the old images and yet another example of the contemporary chimera.

Identity figures uppermost also in Friendship Forever, the only one of the 11 exhibits related to the Osh tragedy. Nailed into the wall are two Central Asian hats, one the Uzbek tyubeteika, the other the Kyrgyz kolpak. The text of the work reads how:

'Friendship Forever' draws on the frequently used national symbols - the Kyrgyz kolpak [national hat] and the Uzbek tyubeteika [national hat], which were tightly nailed together. Our history and fate united us and we cannot do much about it, just learn to live together!

One visitor explained how they found it 'a violent piece' while another termed it 'a fatalistic installation', ethnic groups as 'condemned' to live together. Fears are heightened at a time of revolution, when individuals are asked to think about who they are and where they belong.

Resignation and cynicism mark the fourth and final stage of the revolutionary process, and are captured in two works that feature the country's outgoing and incoming presidents.

In Reprint the accompanying text reads that a "[C]oloured" Revolution took place on the $24^{\text {th }}$ of March 2005 in Kyrgyzstan. One president was replaced by another. The old image was replaced by a new one. Reprint...' A 'plus ça change...' emotion, one visitor stated. Not 
far away is hung the torn picture of Akaev, Repairing Akaev, where visitors were encouraged to assemble the pieces of the Akaev poster. The torn pieces at the end are still visible: the past cannot be reconstituted.

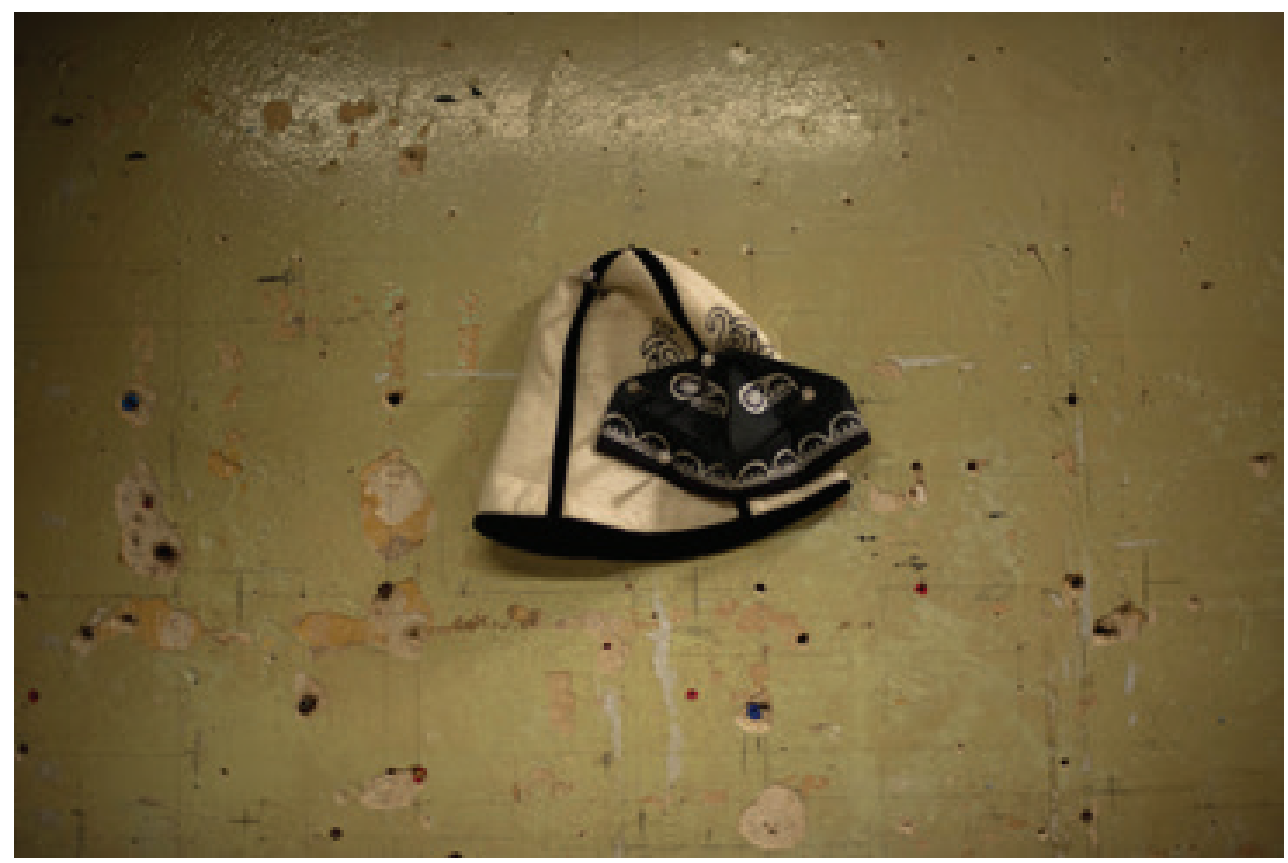

Image 4. Friendship Forever

\section{Other works in the same genre and other works by the same author}

The texts and images by themselves furnish knowledge, but the interpretation process is also helped by references to other works by the same author or in the same genre, references that may be made consciously or unconsciously by the exhibition visitor. Reference to other works by Tursunov and Boikov proved less helpful to our process of interpreting these texts than a comparison with other works. This is because the exhibition commissioned installations which were atypical rather than typical for the two. More helpful, however, is to situate their works comparatively with other conceptual art. Elsewhere, the technologies used, such as videos and photographic prints, are familiar to a London audience, as is the combination of image and text in conceptual art. Also, certain objects or themes are familiar, such as Picasso's dove of peace or the use of nails in hats.

Unlike contemporary art produced by Kyrgyz artists, however, these installations are notable for their absence of references to Kyrgyz traditions, notably the Kyrgyz national epic, Manas. Talip Ibraimov (2007: 111) argues that

Kyrgyz art has been stifled by its frequent references to Manas because it is unacceptable to build an ideological work on the basis of one's own exclusivity - it irreparably damages the public consciousness locking in its own self-complacency, weaning off from the energies of deliberations important for progress. ... it attests to a serious societal disease - an inferiority complex and the political elite's inability to understand that such a complex should be overcome... 
This tendency is in part explained by the republican elite's search in the early independence period for representations of 'cultural authenticity' that would differentiate its republic from their northern neighbour. Boikov and Tursunov, by contrast, do not produce an experience that comforts, but instead one that unsettles and provokes. They do not draw heavily on linguistic, literary or other cultural conventions (Beardsley 1970). Kendall Walton (1989: 413) emphasizes that '[P]erceiving a work in a certain category or set of categories is a skill that must be acquired by training, and exposure to a great many other works in the category or categories in question is ordinarily, I believe, an essential part of this training.' Walton further argues that how an artist intends a work to be categorized is involved in determining the category in which the work is to be perceived 'correctly'. If you know the category then you will perceive something differently.

\section{Exhibition design and display}

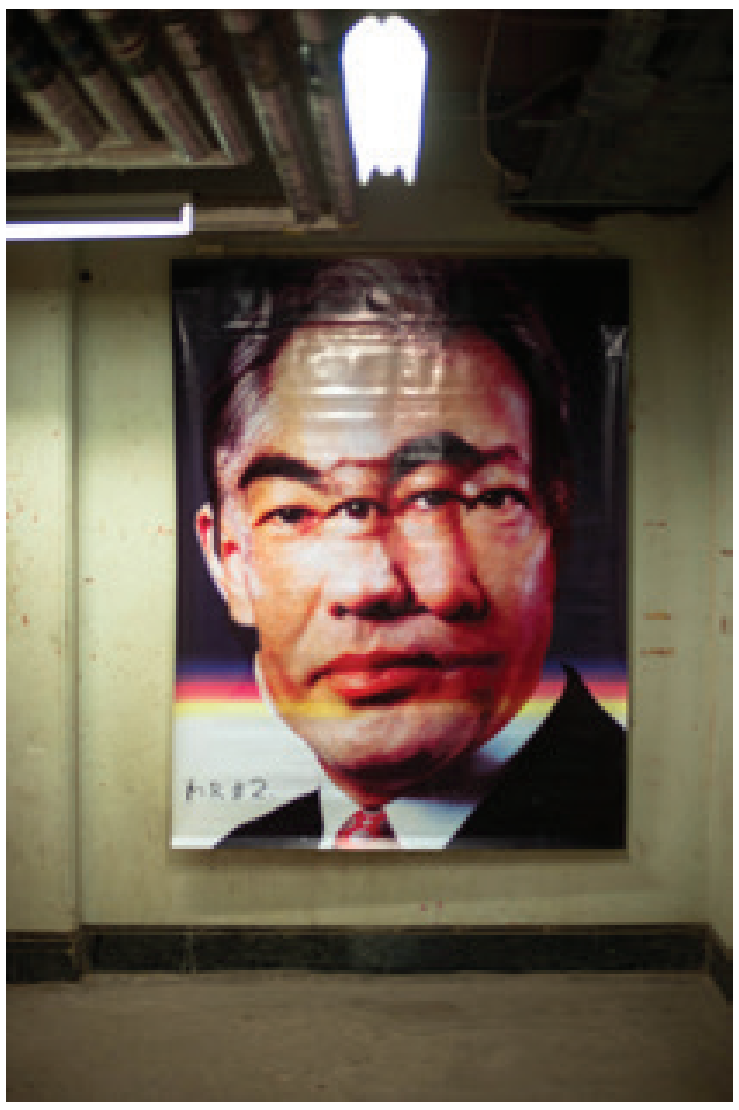

As part of the conceptual art genre, and as briefly mentioned, artists included written text as part of their installations. These texts replaced the labels that a curator might normally suggest including in artistic displays. Michael Baxandall (1991) writes of how an exhibition is a social occasion between artist, exhibitor and viewer. The artist (in Baxandall's article, a craftmaker) understands their culture more immediately and spontaneously than any outsider can (exhibitor or viewer) - even if the importance of training exhibition goers is acknowledged (Charman and Ross, 2006). Much of their understanding of it takes place without rational selfconsciousness, much of his knowledge of it is dispositional. Baxandall (1991: 41) argues that '[E]xhibitors cannot represent cultures. Exhibitors can be tactful and stimulating impresarios, but exhibition is a social occasion involving at least three active terms.' While SvetlanaAlpers(1991) proposes there should be no labels, the art given space to speak for itself, Baxandall (1991: 37) sees the viewer, maker and curator coming into contact 'in the space between object and label'. In the case of (...)Ketsin!, however, this triangularity is absent. In this Image 5. Reprint exhibition the label is still a space but it is a space between artist and viewer, rather than between artist, viewer and curator. The viewer considers the aim of the curator, but not in the space of the label. The viewer, moving between object and label, is highly active and not passively instructed. Labels in (...)Ketsin!, are of two types - primarily they are to be considered as within the conceptual art itself or, occasionally, they are separate and designed to describe and explain the accompanying works. When the latter, they contain a brief description of materials used and dimensions. These could be communicated transnationally. Baxandall (1991: 39) writes how '[T]he purest causes - the least contaminated by our own culturally determined conceptualizations - are the material 


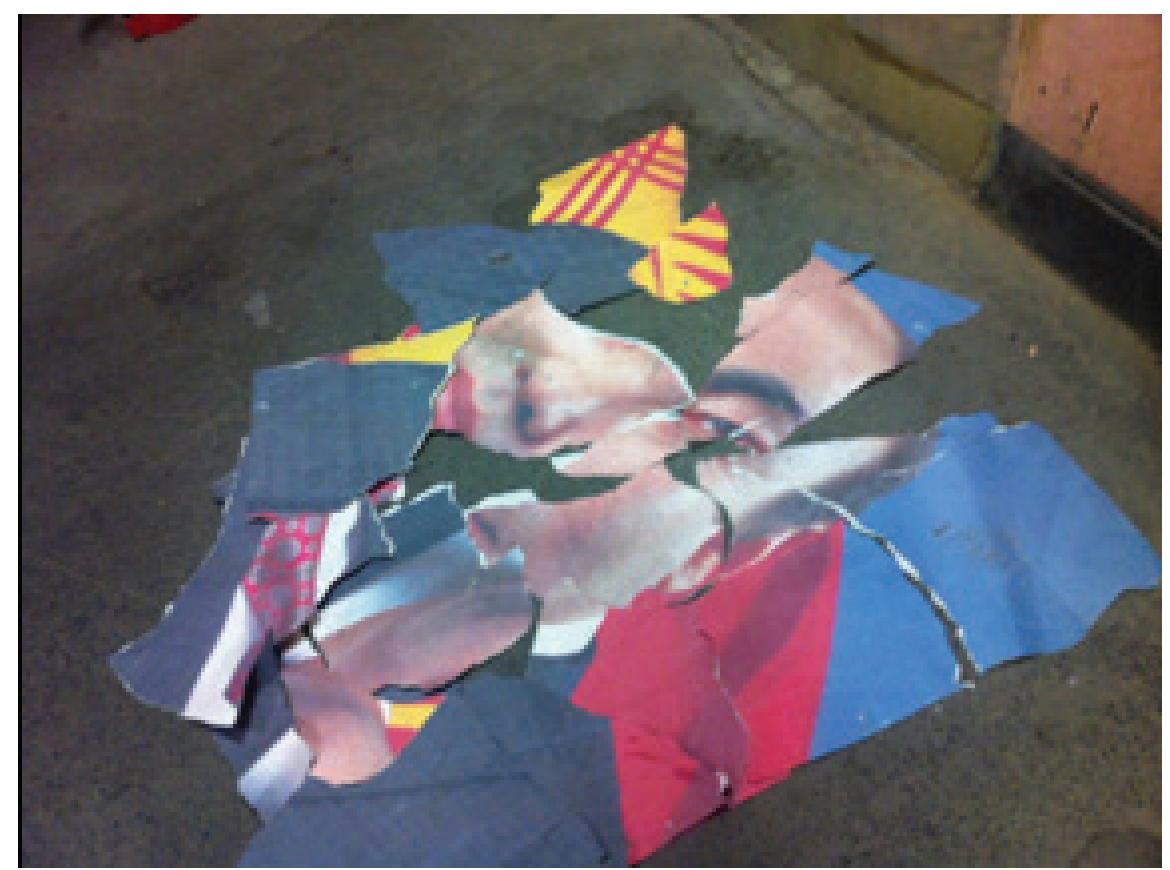

Image 6a. Repairing Akaev (i)

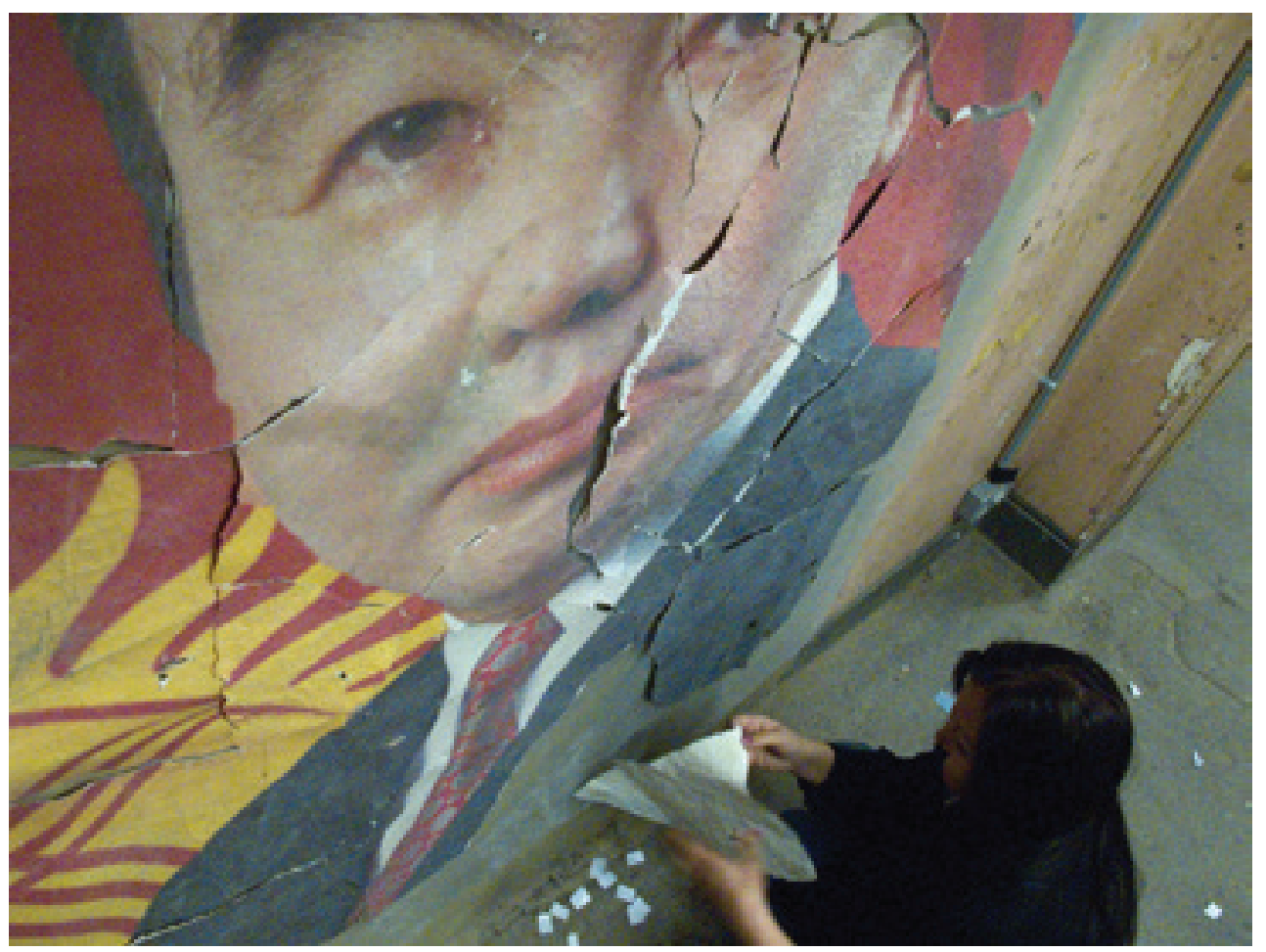

Image 6b. Repairing Akaev (ii) 
causes. Names may differ, but an 80-20 copper-zinc alloy is transcultural both as a concept and in its properties'. But, in large part, labels were more explanatory than descriptive. In some cases, such as Beneath The Skin, their inclusion was fundamental to the interpretation of the work. In other cases, such as Revolution Museum or Asian Eyes, they may have weakened the art piece by offering, it seemed, a contradictory interpretation or a too narrow one. They ended up sometimes creating a tension with the works that left the onlooker often unsure or unsatisfied. But because the labels are explanatory and therefore not directly descriptive of the object, some intellectual space between label (in its extended sense) and artifact does nevertheless remain.

\section{The architecture of the venue}

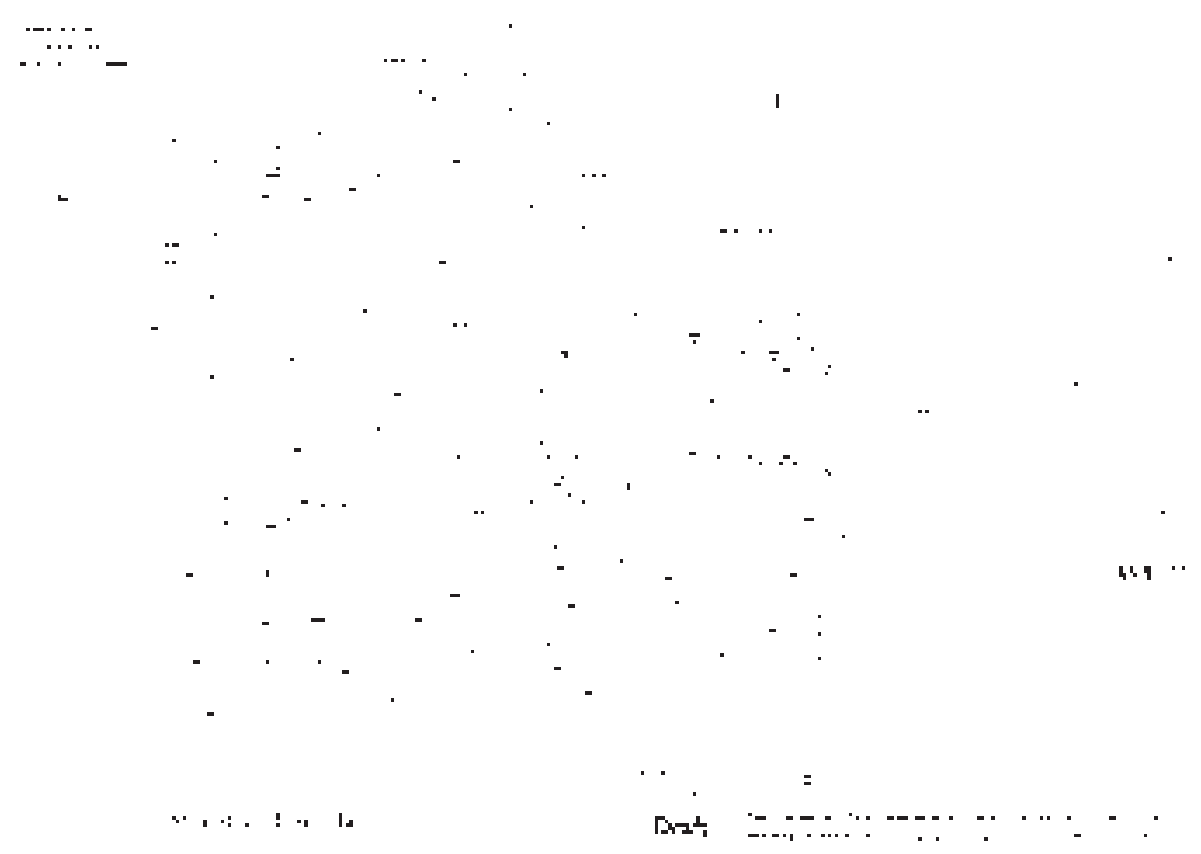

Image 7. Basement Plan Design

If labels can affect interpretation, what about the immediate surroundings of the displays? Shoreditch Town Hall, built in 1865 and extended in 1903, became surplus to requirements in 1965 when Shoreditch Council was merged with Hackney. That brought to an end one of the oldest town councils in British history. After a brief stint as one of the busiest and most popular boxing rings in East London, it was taken over by a trust in the 1990s.

As noted by Barry Lord and Gail Dexter Lord (2002: 69), visitor experience 'begins as the visitor approaches and enters the museum' and that Shoreditch is entered almost secretly conveys a feeling of conspiracy. Kevin Moore (2000) argues that text should be presented judiciously and in an aesthetically pleasing manner. The audience, however, cannot be controlled; even if artists and curator devised an elaborate plan for walking through the basement (some 50 rooms) many preferred not to follow it. Shoreditch has its own 'secret entrance' off Old Street, and a street level access to Rivington Place, and operates as an entirely independent section to the rest of the building. The sensory journey begins with the descent of a set of stairs to reach the entrance of the space. Falk and Dierking (2000: 123) write how 'the visitor's experience is influenced by the creation of space'. 
The setting for the exhibition was intentionally chosen. Completely removed from the white cube aesthetic, it encompasses some 50 interconnecting rooms and alcoves, mostly left untouched and distressed with features such as fireplaces and ranges. Book cases are surrounded by bare brick walls where old wallpapers peel away. These create a highly atmospheric subterranean setting (Shoreditch Town Hall Catalogue 2012: 12). The uneven stonework leads to a narrow external corridor and the door to the exhibition. Inside the lowlit passage is almost as much an artwork as the artwork itself. The mottled, par-painted and subsequently peeling, flaking walls, resemble a tapestry of history not only metaphorically but physically. ${ }^{5}$ The labyrinthine arrangement of rooms makes each viewing space unique, 'enabling sudden encounters with certain works and accidental entrapment with others. ${ }^{6}$

The effectiveness of Revolution Museum, with its message of surveillance, was considerably increased by being placed in a darkly lit room which conveyed some unease and mystery. To cite Lord and Lord (2002: 167), whether to use natural light 'revolves around conservation issues... as well as aesthetic issues', with light directing the viewer's gaze and enhancing the sense of time, place and other contextual influences.

The Shoreditch setting exerted a variety of effects that influenced, and in turn were influenced by, interpretation. It served to reinforce the general emotion the artists wished to convey - sporadic hope in an overall cynical resignation of more of the same. One visitor referred to 'its edginess and unorthodox nature which may have led to achieving the opposite of the artists' intentions - namely that the artists are engaging in agitprop and wish to unsettle and incite change.' Another concluded that 'the architecture may have overshadowed the art itself.' Here the venue becomes entangled with the art in the interpretation process.

\section{The artists' intentions}

The artworks as autonomous products and their categorization both place emphasis on meaning as derived primarily from the content and form of the art itself. The immediate setting stresses physical context. Some would argue, however, that the artworks are as much, sometimes only, the product of the author's intention. One such proponent is E.D. Hirsch (1967), who argued that it is the intention of the author that above all determines what a particular text means. For example, in the case of this exhibition, the poses of the individuals in Kinematics of Protest could, as indeed some exhibition goers did, be interpreted as dance moves. When I mentioned this interpretation to the artists they smiled, but explained these were photographs taken during the protests themselves. For Hirsch this would mean that this pose can only signify protest and hence for him, therefore there would be no issue of entangled meanings.

Some fifty years ago William Wimsatt and Monroe Beardsley launched a celebrated attack on Hirsch. Entitling their article 'The Intentional Fallacy', they declared roundly that 'the design or intention of the author is neither available nor desirable as a standard for judging the success of a work of literary art.' George Dickie and W. Kent Wilson (1995: 468) then added to this debate by underscoring why ascertaining intention is a pointless exercise for at least the following four reasons: first, only what the text says matters; second, the meaning of the text changes; third, the author's meaning is inaccessible; and, fourth, the author often does not know what (s)he means.

To illustrate the first, if intention mattered, then why does the ballerina fare no better who says she was trying to provide comic relief when she falls down in the middle of a serious ballet? Or, to take Isabel C. Hungerland's (1955: 736) example, what of a child producing a clay figure it can identify, when the onlooker, however, is unclear on 'how to look at it' and says it appears as a 'jumble'?

Furthermore, the meaning of the text can change over time. In conversations with the artists, I observed how they came to interpret their works differently. This was partly a function of their work being superseded by events (particularly 2010 and Osh), partly the lengthy gestation period, as the artists kept up their day jobs of commercial orders. Over time, also, the raw emotions experienced at the time of the revolutions were replaced with emotional memories which incorporated a layer of reflection and digestion that could transform how the event was experienced - and then interpreted.

Biographies and questions directly posed to the artists also proved poor indicators of the artists' intentions. Born in 1960 in the Kyrgyz SSR, Boikov moved with his parents a year 
later to Baku Azerbaijan where he spent the next 20 years of his life. His father served in the army, where Evgeny also did his required service after deciding to major in sport, completing the Azerbaijani State Institute of Sport Science. Returning to the Kyrygz Republic in 1982, he started his career in painting, which was to consume him for the next 30 years. By contrast, Tursunov spent his childhood in the Kyrgyz SSR, before proceeding to win a place to study cinematography at Moscow's prestigious VGIK (All-Russian State University of Cinematography named after S.A. Gerasimov) and, after working in Mosfilm Studio, created his own production company in Bishkek, Ordo.

These biographies could suggest, for example, that the period Tursunov spent at Mosfilm as the Soviet Union collapsed around him imparted upon him a particular understanding of art. To what extent were these artists' biographies explained through the lens of socialist realism, which Margaret Bullitt (1976: 53) describes as characterized by 'its steadfastly optimistic and frankly tendentious approach to human experience, its identification of aesthetic worth with "ideological correctness," and its enforced harmony of aesthetic expression with current party policies.' But none of this seemed to fit the objects at the exhibition. Indeed, instead of expressing artists' lives, the exhibits may have tried to do the exact opposite, in that theartists may well have distanced themselves from their lives when they create their artworks .

The more that such connections between biography or stated intention and output were made, the more it 'seemed virtually impossible to find nonspeculative connections' (Stecker 2008: 310). My artists disliked being quizzed about their own works and they may well have offered insincere and misleading answers. Even in the most intimate conversations I was privileged to share with them I was unable to bridge the private and public domains. The only consistent statement they would make is that their art was not intended as agitprop; in other words, they were not advocating political activism through art (which the title of the exhibition might have suggested and which they recognized) on the lines of Kylie Message's (2013) analysis of 1960s and 1970s museum activism in the National Mall, Washington DC. Anne Sheppard (1987: 109) acknowledges that what artists consciously have in their mind is very difficult, if not impossible, to know, elaborating on how '[e]ven where such statements are available they are often unreliable.' One visitor to the exhibition stated: the work is bleak. The artist said - it was not intended to be bleak. The upshot is multiple interpretations. The exhibition may be accidentally bleak, but it is questionable that it can be called unqualifiedly bleak simply because the artists say it was not so. A useful compromise approach is Berys Gaut's (1993) patchwork theory, which places emphasis on local theories of interpretation over any universal canon of interpretation. Recognition of the artists' intention is not a necessary condition for the knowledge of linguistic meaning.

\section{The roles of commissioner, sponsor and curator}

The artists' are not the only intentions to consider; there are also those of the commissioner, sponsor and curator. These are often three separate people in the mounting of exhibitions. For example, a larger museum may commission a particular exhibition and enlists its fundraising section to financially support it and someone from its list of curators to organize it. A smaller art gallery might commission a curator to bring to the gallery an artist or set of artists and, through sale of this art, to part finance the exhibition.

(...)Ketsin! departed from both models. While Shoreditch was the venue, the Town Hall did not commission the exhibit. Instead, I was both commissioner and curator and, since I conceived this as a research product, I sought research funding. These details of the commissioning stage hold further implications for the process of interpretation. First, funding by UK academic research bodies gave the artists (and curator) an enormous degree of freedom in deciding the content of the exhibition. For example, in transcultural exhibitions, particularly those of political events, local representatives of the countries being represented, e.g. local embassies, often become part-sponsors of the exhibition and then often stakeholders of the content. Had political elites of Central Asia been involved in the sponsorship and design of (...)Ketsin!, its content may have been altered.

Because the exhibition consisted of works that were specially commissioned, the intended audience was bound up with the curator's ideas about the nature of that audience and the attendant display (s)he envisaged. The curator's aim was to mount a display that 
combined education with experience (Serota 2000): through an aesthetic experience the visitor in London should depart with a sense of the essence of the revolution. In Steven Dubin's (1999: 3) terms: 'Images can intensely compress complex ideas and sentiments. They often project what Walter Benjamin called aura, an elusive, charismatic and sometimes haunting presence.' Visitors referred variously to 'an experience', a 'sense', an 'impression', rather than to having gained any more specific knowledge about the details of the revolution. As such, the idea of forced harmony, compressed into the two hats nailed together, does not provide us with details of the Osh June 2010 violence, but it does convey that for these artists at least intercommunal living is unavoidable if further bloodshed is to be avoided and that the fates of the Uzbeks and Kyrgyz are ineluctably rather than voluntarily entwined. As such, many visitors described their viewing as a type of aesthetic experience or 'interest without ulterior purposes' (Carroll 1999: 171).

The importance of curators and consultant interpreters in shaping interpretation is captured in audience-based museum research. For example, when curators have begun to work with advisory groups for exhibitions, '[W]ith this backing, the exhibition team-leader has a strength and a power to carry through the concept of the exhibition that is not forthcoming in other ways' (Hooper-Greenhill 1994: 22). Graham Black (2005: 3), based on his experiences as a consultative interpreter, traces the pressures that have developed to change the perceptions of the public and offers that ' $[T]$ o be audience-centred means taking into account the personal context of the visitor and the holistic nature of the museum visit'. Meszaros (2006: 15) similarly calls upon the curator to assist in establishing 'interpretive authority' and in 'making visible the interpretive repertoires that [the museum] creates and circulates in culture.' With the labels already supplied and the artists happy with the choice of Shoreditch, I deliberately chose not to interfere practically either with label design (part of the conceptual art in any case) or with display arrangement.

What I did encounter, however, were certain situations as a contextual interpreter. When present with the artists at the exhibition and asked to interpret for them from Russian, I would often find myself tempted to preface my interpretations with 'To give you first a little context...' Making conscious sense of the unconscious, you could call it. Later, I thought about why I felt impelled to do this, and realized it was because I saw myself as trying to portray to the very intelligent onlooker also the context in which this art was born. Kyrgyzstan is a young republic of no more than 4 million people that has flirted with liberalization and attempted democratization, but is flanked on both sides with large authoritarian states, Russia and China. This makes their experiment hard. But the Chinese are regarded with a mixture of suspicion and resignation, suspicion about historical mapping of Central Asia as part of their territory and post-independence secret negotiations between Beijing and Bishkek that has led to border territories being withdrawn and territory ceded to China. The resignation, however, sets in as Chinese goods flood the Kyrgyz market, and the Chinese government becomes the only government to build roads and railways, Central Asia's 'public goods provider' (Cooley 2012: 87).

A particularly noticeable example came with the exhibit Asian Eyes. This image had also been chosen by the artists to act as display poster outside Shoreditch. The visitor I was interviewing, internationally successful in the world of business, well-traveled and from London, found the images 'racist' and therefore 'offensive'. The appellation to the Asian eye, he said, was a negative stereotyping and biological differentiation that did not fit with his view of multiculturalism. The artists, by contrast, did not see the exhibit in this way. Some of the text asks: 'What is it? An Asian glance? A global spread of the Chinese influence? Or the cosmopolitan stance of the European civilization which has partly developed Asian features?' These references display the search for cultural authenticity as new identities are renegotiated, as the young Republic is given the opportunity to establish itself on the world arena. In this establishment comes a cultural positioning: are we European or Asian? The portrayal suggests a strong, or at least growing, Chinese influence in Kyrgyz culture, and a discomfort with that growth.

I wanted to forefront the aesthetic by commissioning the artists to convey the contradictory emotions around the experience of revolution, primarily through resonance rather than wonder. B.N. Goswamy (1991: 72) usefully distinguishes between the former as 
the power of the displayed object to reach out beyond its formal boundaries to a larger world, to evoke in the viewer the complex dynamic forces from which it has emerged and for which it may be taken by a viewer to stand

In this exhibition, this became more important than wonder, the 'power of the displayed object to stop the viewer in his tracks, to convey an arresting sense of uniqueness, to evoke an exalted attention'.

In the months that followed, we all had our share of doubt and uncertainty. I was unsure of how well the idea of (...) Ketsin! was going to come across to London audiences. I was fearful that the exhibition might become too wordy and the concept might overshadow the art. I was also worried that we were exploring a given period in depth through installations to an audience generally unfamiliar with the history of the Kyrgyz Republic. But messages about political change through affect did seem to be getting through. A renowned London-based photographer writes:

I get a sense that they are identifying with the ordinary people rather than the powerful. There is a distance or detachment from the process or drivers of change, perhaps even helplessness. These are reflections on the experience of state power and the uncertainty (and violence) of change, and the impact this may have on the ethnic and power balances of the country. The works suggest the artists want peaceful coexistence, do not trust politicians and are fatalistic about sudden change. I see and feel expressions of fear, distrust, oppression, change, flux, violence. This is about change that is not resolved....The substructure (and experience) remains the same even if the appearance of the superstructure is changing (back and forth). (personal communication on 31 January 2014 with the author)

\section{The split audience: original and intended}

William Tolhurst (1979:11) argues that a text only acquires meaning with an audience, namely:

utterance meaning [textual meaning] is best understood as the intention which a member of an intended audience would be most justified in attributing to the author based on the knowledge and attitudes which he possesses in virtue of being a member of the intended audience.

Those writing on aesthetics, intention and art criticism refer to the 'original' audience as a further factor influencing the process of interpretation, not least because the original audience is often assumed, or indeed ends up being, the same as the intended audience. To cite Sheppard again (1987: 110):

The artist produces his or her work to be understood by an audience. At this point the audience's expectations re-enter the picture. An artist will use the forms and conventions of his or her own day, following the moral, social, and political assumptions of the time, not only because this is what he or she knows, but because this is what the audience know.

A proper appreciation of Boikov and Tursunov in this line of reasoning requires an appreciation of post-Soviet Kyrgyzstan - even if an exhibition requires no previous knowledge as it is intended to invite the visitor to something new and unfamiliar, the experience of the onlooker will differ according to their prior knowledge of this country.Post-Soviet Kyrgyzstan differed from its neighbours in having allowed artists considerable freedom of expression in the era of the first post-Soviet president, Akaev, a trend that continued, but only by default, after his replacement by Bakiev. While no longer financially supported by the Kyrgyz government, artists did look back at the Akaev era with general fondness, as an era which permitted unprecedented exploration in new content and forms. Bokombaev (2007: 112) writes how the Akaev era temphasized that '[O]ur common culture is the one of visual images, understandable without words, and this is what determines its most distinctive characteristics.' It was an epoch that 'democratized processes in the artistic environment'. 
The political and conceptual possibilities and creative spaces narrowed under Akaev's replacement Bakiev partly because Bakiev did not place emphasis on building new ideologies and discourses of identity, and partly because tangible curtailments of press freedom and assembly rights worked their way into a spirit of authoritarianism from which the artists recoiled. When Bakiev turned out to be more corrupt than his predecessor (International Crisis Group 2010) the artists felt destined to convey how every revolution produces the same. The poster on the Presidents expresses this cynicism. The original audience is the audience of the Kyrgyz Republic, aware of the values and conventions of the artist and who interpret the art within their own repertories. The original audience captures the importance of museums' sensitivity to local communities (Golding and Modest 2013). For (...) Ketsin! the original audience was not the same as the intended audience. To a large extent, the exhibition was not produced with the original audience in mind. While discussions on intentionality and art have tended to focus on the original audience, in the context of a specially commissioned, transnational exhibition, the intended audience is also critical.

The intended audience was, on the whole, an audience ignorant of the original audience, be it in terms of local conventions or local social and political contexts. The London visitor was assumed to have no assumptions about the Kyrgyz Republic. As such, they would have a poor stab even at hypothetical intentionalism, which is what an audience would understand to be intended, given certain background assumptions (Levinson 1992; Tolhurst 1979). The cited conversation with the international businessman illustrates the implications of negating the significance of context through the conversations we had with one onlooker and his interpretations of one of the exhibits. If onlookers on the whole arrived uninformed about the politics of the Kyrgyz Republic they did, however, come with other analytical toolkits. For example, the art critic who came to the exhibition used the rules they had acquired to interpret the exhibition. These art critics often chose to interpret works in different ways to what the text of the authors suggested. As Hungerland (1955: 741) writes: 'An author's way of regarding his work may or may not be the one which makes me rate it more highly and like it better than do competing interpretations.' Even if the labels wanted to convey a certain message, audience members often found in the pictures things they themselves wanted to see. The title of the exhibition for the original audience would simply have been (...)Ketsin! but for the intended audience 'Art from the Kyrgyz Republic' was added, since the London audience could not expect to identify the word as being Kyrgyz.

\section{Conclusions}

(...) Ketsin!, although containing objects, uses these as installations rather than as museum displays. While some of the issues of translating cultures are similar in a museum as a gallery, an exhibition focused around works of art sets its own particular challenges for translation. It has its own attributes working together to create knowledge. A transnational art exhibition foregrounds three particular tensions that become entangled: the tension between the art and the space where it is displayed; the tension between art and message, with the questioned role of author intentionality; and the question of a split audience that brings different cultural experiences to the viewing process.

Stephen Davies (2006: 231) claims that by restricting an interpretation to what the artist wanted we minimize enjoyable aesthetic experience - an experience shaped by the act and process of exhibiting. In Moser's (2010: 31) words:

Displays create new worlds for objects to inhabit and these worlds are full of 'devilish details' that really matter when it comes to creating a system of meaning relating to the subject being represented. Far beyond being mere trifles in the scheme of manufacturing knowledge, the attributes of museum display have long asserted themselves as key epistemic devices.

In particular, we can tentatively posit that when art works themselves are unclear, viewers will resort to either an educational experience through intense reading of the labels or an emotional experience which can draw as much and sometimes more on the place and display properties than the piece itself. One key factor behind whether they resort to either education 
or emotion is the extent of their own knowledge about the place from where the art comes. This echoes Sheppard (2009: 78-9), when she writes that '[F]ailure to appreciate unfamiliar literature often arises from our natural tendency to extrapolate from the works we know to the unfamiliar works, to judge the unfamiliar by criteria derived from the familiar.'

The London audience reevaluates their own knowledge in seeing. Ivan Karp (1991: 22):

Almost by definition, audiences do not bring to exhibitions the full range of cultural resources necessary for comprehending them; otherwise there would be no point to exhibiting. Audiences are left with two choices: either they define their experience of the exhibition to fit with their existing categories of knowledge, or they reorganize their categories to fit better with their experiences.

The contexts and resources that reorganize knowledge in the case of this exhibition included: Shoreditch; the accompanying texts; and, universal tropes on revolution known to the average visitor but with a strong individual and Kyrgyz flavour. The picture advertising the exhibition on Facebook - a print from Kinematics of Protest - could have been a protester from anywhere. At the same time, specifically Kyrgyz themes, such as the Osh riots, were conveyed in forms that resonated rather than wondered - the nailing of objects to a wall has been done elsewhere. Emotion was conveyed through resonance of emotions stirred (helped by the atmosphere of Shoreditch) rather than wonder evoked by the power of art. The exhibition sought resonance rather than wonder.

Through resonance and emotion the exhibition imparted certain ideas about the Kyrgyz revolution. First, perception and subjectivity mattered enormously as events unfolded and as they are interpreted in retrospect. The interpretation of the artist, curator, audience member is of paramount importance when understanding how particular events are interpreted and how they can be used by political forces. The one message the artists had been keen to convey was that they were not political activists. The title (...)Ketsin! for the original audience, notably the political leaders of the original audience, conveyed the exact opposite, however. Indeed, artists and curator alike were contacted by political activists in the region, because their encounter with the exhibition's title had made them assume this had been the artists' goals. The Shoreditch location unwittingly contributed to these goals.

The pieces questioned whether what had happened constituted a revolution itself. This reflects debates in political science literature (Cummings 2010; Radnitz 2006) which shows the differences between the Kyrgyz revolution and the other so-called colour revolutions of Georgia, Serbia and Ukraine. Kinematics of Protest, with the hopes of change and movement and power invested in the individual, contrast with the continuities of Reprint, where different presidents end up producing similar corrupt politics, and where politics is displaced from the people to the presidents and highly personalized power. The exhibition did not produce images that the ruling regime would have felt comfortable using to support its own narratives to legitimate its rule.

Instead (...)Ketsin! conveyed a country beset by crises of identity and deep-seated memories of protest and violence, expressed for example in Beneath My Skin and Friendship Forever. Insecurity of the self and the 'other' permeated the exhibition, for example in Revolution Museum and Asian Eyes. While 2005 and 2010 displayed politically quite different features, such as different triggers (the first, electoral fraud, the second, price rises) and different immediate effects (e.g. power-sharing after 2005 compared to a tabula rasa in 2010), these differences were lost on the artists, who sought to convey instead their stark similarities. Thus, revolutions are conveyed as cyclical with a certain popular resignation of politics delivering more of the same, for example, Reprint, Repairing Akaev, with an only very occasional glimmer of hope, e.g. Dove of Peace. In all this, revolution is not the crowd but the individual, and the individual is under surveillance or, because alone, ultimately ineffective, e.g. Revolution Museum, Kinematics of Protest.

The experience of (...)Ketsin! Suggests the importance of the way in which exhibitions are conceived. The role of the parties (curator, audience - original and intended - and the artists) and the performance of the exhibits (in terms of venue and display type) have a profound impact on the production of knowledge through art. These factors are entangled: visitors may 
have stressed one factor more than another, but at the same time often acknowledged that it was impossible to separate aesthetic qualities from display, or intentionality from message. The medium of communicating these messages is inseparable from how the texts are read and interpreted. (...)Ketsin! was neither exclusively a vehicle for the display of objects nor a space for telling a story, it was a little of both. The event hinted at the difficulties of establishing any one interpretation as correct, and whether this is a legitimate exercise in any case. This does not mean that viewers left (...) Ketsin! with a 'whatever' interpretation, but it did strongly suggest there was no one correct interpretation.

Received: 11 June 2014

Finally accepted: 9 June 2015

\section{Notes}

1 My thanks to the generous support of Glasgow University's Centre for Russian, Central and East European Studies (CRCEES), the British Academy and the Arts and Humanities Research Council, and specifically to Richard Berry and Ann Mulholland. My thanks also to the Honeyman Foundation for a pilot grant. I am grateful to Berys Gaut (StAndrews University), Ali Iğmen (California State University), Stephanie Moser (Southampton University) and Alexander Nagel (Smithsonian Institution) for insightful comments on an earlier iteration. I also benefitted from audience questions at three related presentations: Bordeaux ECPR (4 September 2013), George Washington University (1 May 2014) and Oxford University (Paul Bergne Memorial Lecture, 7 May 2014). Comments by anonymous peer reviewers were very stimulating and helpful. My thanks also to John Collis for introducing me to Shoreditch and his later practical assistance. Mark Cummings provided useful advice on the layout of Shoreditch. Claire Alder and George Howard helped enormously with the logistics and marketing of the exhibition.

2 Personal context: 1. Visit motivation and expectations 2. Prior knowledge; 3. Prior experiences; 4. Prior interests; 5. Choice and control; Sociocultural context: 6 . Within group social mediation; 7. Mediation by others outside the immediate social group; and, Physical context: 8 . Advance organizers; 9 . Orientation to the physical space; 10. Architecture and large-scale environment; 11. Design and exposure to exhibits and programs; 12 . Subsequent reinforcing events and experiences outside the museum.

3 These are the: Accountive, Constructive, Classifying, Interpretive and Re-creative.

46 of the 15 were known previously to the author (2 academics, 2 artists and 2 art critics, all from the UK). The remaining 9 were randomly selected over the week: 2 international business workers from the UK and resident in London; 2 Kyrgyz students temporarily studying in London; 3 art critics from the UK; and, 2 artists from France and UK.

5 http/www.an.co.uk/interface/renews/single/1838479

6 http://www.spam

\section{References}

Alpers, S. (1991) 'The museum as a way of seeing', in Ivan Karp and Stephen K. Lavine (eds) Exhibiting cultures: The poetics and politics of museum display, 25-32, Washington D.C.: Smithsonian Institution Press.

Ames, M. M. (1992) Cannibal tours and glass boxes: The anthropology of museums, Victoria: UBC Press.

Anon. Hall, Shoreditch Town. (2012) Shoreditch Town Hall Catalogue. London. 
Baxandall, M., \& Chester, W. (1988) Painting and experience in fifteenth century Italy: a primer in the social history of pictorial style, Oxford: Oxford University Press.

Baxandall, M. (1991) 'Exhibiting intention: Some preconditions of the visual display of culturally purposeful objects', in Ivan Karp and Stephen K. Lavine, (eds) Exhibiting cultures: The poetics and politics of museum display, 33-41, Washington D.C.: Smithsonian Institution Press.

Beardsley, M. C. (1970) The possibility of criticism (Vol. 72), Detroit: Wayne State University Press.

Black, G. (2005) The engaging museum: Developing museums for visitor involvement, London: Psychology Press.

Bokombaev, G. (ed) (2007) Epokha, (2007) Bishkek: AziyaUniversalBank Press.

Bullitt, M. M. (1976) 'Toward a Marxist Theory of Aesthetics: The Development of Socialist Realism in the Soviet Union', Russian Review, 35(1) 53-76.

Charman, H, and Ross, M. (2006) 'Contemporary Art and the Role of Interpretation: Reflections from Tate Modern's Summer Institute for Teachers', International Journal of Art \& Design Education, 25(1) 28-41.

Cooley, A. (2012) Great Games, Local Rules: The New Great Power Contest in Central Asia, Oxford: Oxford University Press.

Cummings, S.N. (ed) (2010) Domestic and International Perspectives on Kyrgyzstan's 'Tulip Revolution': Motives, Mobilization and Meanings, London: Routledge.

Davies, S. (2006) 'Authors' intentions, literary interpretation, and literary value', The British Journal of Aesthetics, 46(3) 223-247.

Dickie, G., \& Wilson, W Kent. (1995) 'The Intentional Fallacy: Defending Beardsley', Journal of Aesthetics and Art Criticism, 53(3) 233-250.

Dubin, S. C. (1999) Displays of power: Controversy in the American museum from the Enola Gay to Sensation, New York: NYU Press.

Falk, J. H, \& Dierking, L.D. (2000) Learning from museums: Visitor experiences and the making of meaning, D.C.: Rowman Altamira Press.

(2008) in Loïc Tallon (ed), Digital Technologies and the Museum Experience: Handheld Guides and Other Media, 19-34, D.C.: Rowman Altamira Press.

Gaut, Berys (1993) 'Interpreting the arts: The patchwork theory', Journal of Aesthetics and Art Criticism, 51(4) 597-609.

Golding, V., \& Modest, Wayne (2013) Museums and communities: Curators, collections and collaboration, London: A\&C Black.

Goswamy, BN. (1991) 'Another past, another context: Exhibiting Indian art abroad' in Ivan Karp and Stephen K. Lavine, (eds) Exhibiting cultures: The poetics and politics of museum display, 68-73, Washington D.C.: Smithsonian Institution Press.

Hirsch, E.D. (1967) Validity in Interpretation, New Haven, CT: Yale University Press.

Hooper-Greenhill, E. (2013) Museums and their visitors, London: Routledge. 
Housen, A. (1983) The eye of the beholder: Measuring aesthetic development (Doctoral dissertation, Harvard Graduate School of Education).

Hungerland, I. C. (1955) The concept of intention in art criticism. The Journal of Philosophy, 733-742.

Ibraimov, T. (2007) 'Ghosts' in Gamal Bokombaev (ed), Epokha, 7-9, Bishkek: AziyaUniversalBank Press.

International Crisis Group (2010), Kyrgyzstan: A Hollow Regime Collapses, Asia Briefing No.102.

Karp, I. (1991) 'Culture and Representation' in Ivan Karp and Stephen K. Lavine, (eds) Exhibiting cultures: The poetics and politics of museum display, 25-32, Washington D.C.: Smithsonian Institution Press, 11-24.

Levinson, J. (1992) 'Intention and Interpretation: A Last Look', in Gary Iseminger (ed), Intention and Interpretation, 221-256, Philadelphia: Temple University Press.

Lord, B., \& Lord, G.D. (2002) The manual of museum exhibitions, D.C.: Rowman Altamira Press.

MacIntyre, A. (1984) After virtue, Notre Dame: University of Notre Dame Press.

Message, K. (2014) Museums and Social Activism: Engaged Protest, London: Routledge.

Meszaros, C. (2006) 'Now THAT is evidence: Tracking down the evil 'whatever' interpretation' Visitor Studies Today, 9(3) 10-15.

Moore, K. (2000) Museums and popular culture, London: Continuum.

Moser, S. (2010) 'The devil is in the detail: museum displays and the creation of knowledge', Museum Anthropology, 33(1) 22-32.

Serota, N. (2000) Experience or interpretation: the dilemma of museums of modern art, New York: Thames and Hudson.

Sheppard, A. (1987) Aesthetics: An introduction to the philosophy of art, Oxford: Oxford University Press.

Stecker, R. (2008) Interpretation and construction: Art, speech, and the law, Chichester: John Wiley \& Sons.

Tolhurst, W. (1979) 'On What A Text Is And How It Means', The British Journal of Aesthetics 19 (1) 3-14.

Walton, K. L.. (1989) 'Categories of Art', in George Dickie and Ronald Roblin (eds), Aesthetics: A Critical Anthology (Vol. 2nd ed), 394-414, New York: St Martin's Press.

Whitehead, C. (2011) Interpreting art in museums and galleries, Abingdon: Taylor \& Francis.

Wimsatt, W. K, \& Beardsley, Monroe C. (1946) 'The intentional fallacy', The Sewanee Review, 54(3) 468-488.

Yenawine, P. (1997) 'Thoughts on visual literacy', in James Flood, Shirley Brice Heath and Diane Lapp (eds) Handbook of Research on Teaching Literacy through the Communicative and Visual Arts, Macmillan Library Reference. 


\section{Sally Nikoline Cummings*}

Professor Sally N. Cummings teaches at the University of St Andrews. Her current research focuses on the politics of culture and political communication, primarily in Central Asia. Her publications include: Understanding Central Asia (Routledge, 2012); Symbolism and Power in Central Asia: Politics of the Spectacular (ed. Routledge, 2010); Kazakhstan: Power and the Elite (IB Tauris, 2005); and, Kazakhstan: Centre-Periphery Relations (Royal Institute of International Affairs and Brookings Institution, 2000). In 2008 Cummings completed a documentary film on Soviet propaganda and in 2013 she curated a visual arts exhibition on the Kyrgyz revolution. She is founding director of the St Andrews Institute of Middle East, Central Asian and Caucasus Studies.

snc@st-and.ac.uk

School of International Relations

The Arts Building,

The Scores

University of St Andrews

KY16 9AL

Tel: 01334-462921

or 01334-462945 